\title{
Potentiometric E-Tongue System for Geosmin/Isoborneol Presence Monitoring in Drinkable Water
}

\author{
Larisa Lvova 1,2,*D, Igor Jahatspanian ${ }^{2}$, Luiz H.C. Mattoso ${ }^{3}$, Daniel S. Correa ${ }^{3}$ (D), \\ Ekaterina Oleneva $^{2}$, Andrey Legin ${ }^{2,4}$, Corrado Di Natale ${ }^{2,5}$ and Roberto Paolesse ${ }^{1,2}$ \\ 1 Department of Chemical Sciences and Technologies, University “Tor Vergata”, 00133 Rome, Italy; \\ roberto.paolesse@uniroma2.it \\ 2 Laboratory of Artificial Sensory Systems, ITMO University, 197101 St. Petersburg, Russia; drjie@mail.ru (I.J.); \\ ekaterina.oleneva@inbox.ru (E.O.); a.legin@spbu.ru (A.L.); dinatale@uniroma2.it (C.D.N.) \\ 3 Nanotechnology National Laboratory for Agriculture (LNNA), Embrapa Instrumentation, \\ Sao Carlos 13560-970, Brazil; luiz.mattoso@embrapa.br (L.H.C.M.); daniel.correa@embrapa.br (D.S.C.) \\ 4 Institute of Chemistry, St. Petersburg State University, 199034 St. Petersburg, Russia \\ 5 Department of Electronic Engineering, University “Tor Vergata", 00133 Rome, Italy \\ * Correspondence: larisa.lvova@uniroma2.it; Tel.: +39-06-7259-4732
}

Received: 30 December 2019; Accepted: 29 January 2020; Published: 4 February 2020

\begin{abstract}
A potentiometric E-tongue system based on low-selective polymeric membrane and chalcogenide-glass electrodes is employed to monitor the taste-and-odor-causing pollutants, geosmin (GE) and 2-methyl-isoborneol (MIB), in drinkable water. The developed approach may permit a low-cost monitoring of these compounds in concentrations near the odor threshold concentrations (OTCs) of $20 \mathrm{ng} / \mathrm{L}$. The experiments demonstrate the success of the E-tongue in combination with partial least squares (PLS) regression technique for the GE/MIB concentration prediction, showing also the possibility to discriminate tap water samples containing these compounds at two concentration levels: the same OTC order from 20 to $100 \mathrm{ng} / \mathrm{L}$ and at higher concentrations from 0.25 to $10 \mathrm{mg} / \mathrm{L}$ by means of PLS-discriminant analysis (DA) method. Based on the results, developed multisensory system can be considered a promising easy-to-handle tool for express evaluation of GE/MIB species and to provide a timely detection of alarm situations in case of extreme pollution before the drinkable water is delivered to end users.
\end{abstract}

Keywords: taste-and-odor-causing compounds; geosmin; 2-methyl-isoborneol; potentiometric E-tongue; water potability assessment

\section{Introduction}

Water quality control through continuous monitoring is an important analytical challenge, since water is one of the most essential natural resources for humanity [1]. Several directives and legislations governing drinkable water quality parameters are issued worldwide [2-5]. In these documents the main attention is given to the water characterization in terms of polluting species, which may provide serious risks to the health of consumers; however, an important issue is represented by the water organoleptic properties, which can in general give the water "potability". It is evident that consumers would prefer obtaining a transparent and odorless water from their water supply, with no visible suspended species, and be able to consume tap water without any further pre-treatment like filtering, boiling, degassing, etc. Unfortunately, the quality of water provided for human use around the world is not always satisfactory; in many regions, and even entire countries, the degree of water pollution is extremely high, while in other places, the presence of some polluting compounds in water, 
even if not toxic, results in very unpleasant organoleptic characteristics, limiting its potability [6]. Although they are semi-volatile compounds, geosmin (trans-1,10-dimethyl-trans-9 decalol, GE) and isoborneol/2-methyl-isoborneol (IB/MIB) are found among the most taste and odor-causing pollutants of drinking water obtained from surface water (Figure 1) [7]. These compounds have a very strong, musty earthy taste and odor and arise in surface water as a result of several filamentous and cyanobacteria strains metabolites' release and further degradation [8]; moreover GE/MIB have an extremely low odor threshold concentration (OTC) around 10-20 ng/L, while some people can notice their presence at levels up to $4 \mathrm{ng} / \mathrm{L}$ [9].<smiles>C[C@H]1CCC[C@]2(C)CCCC[C@]12O</smiles>

GE

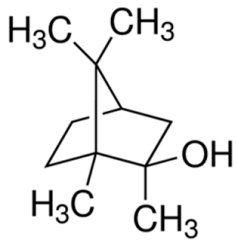

MIB

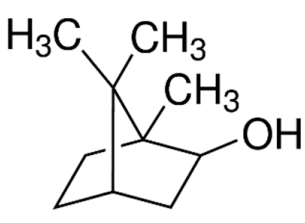

IB

Figure 1. Chemical structures of taste-and-odor compounds: GE: geosmin, MIB: methyl-isoborneol, IB: isoborneol.

At present, there are no regulations on the maximum permitted amounts of GE/MIB in drinkable water, since these compounds are not associated to any negative effect on human health [7]. Nevertheless, due to the very unpleasant taste and odor of drinking water contaminated with GE/MIB, consumers may prefer to purchase bottled water instead of consuming water from public water supplies, thus increasing the amount of waste plastics and overall environment contamination [10]. Nowadays more than one million plastic bottles are bought every minute around the world, with an estimated 300 million tons of plastic every year [11]. The resistance of GE/MIB to elimination through conventional water treatment processes, such as home boiling and filtration, or by coagulation, sedimentation, and chlorination methods employed at water treatment stations, presents a challenging issue to find an appropriate analytical procedure to monitor and predict the presence of these pollutants in drinkable water at levels lower than the OTC level of GE/MIB, to protect both the water consumers and water suppliers.

The conventional instrumental methods, in particular gas chromatography-mass spectrometry (GC-MS), coupled with different extraction/enrichment techniques are widely employed nowadays for the analysis of GE/MIB [12-14]. Unfortunately, despite the evident benefits such as high selectivity and high analytical precision, GC-MS requires costly equipment, qualified personnel, it is time consuming and, especially in a case of GE/MIB detection having very low OTC levels, requires a sample enrichment and pre-concentration. Hence, the development of novel analytical techniques for express and non-costly GE/MIB detection is an important challenge. Recently, some alternative analytical methods were reported, owing to lower costs and the possibility of rapid GE/MIB detection in potable water; for instance, colorimetry with Tortelli-Jaffe bromine-based reaction [15], enzyme-linked immunosorbent assay (ELISA) for geosmin [16] and indirect competitive immunoassay for MIB [17,18], application of chemical sensors [19] and multisensor arrays, e-nose [20,21], and e-tongue [22] in particular. In the last systems, the chemical sensors with different transduction principles are employed in a combination with multivariate data analysis for GE/MIB analytes identification at levels close to the OTC, thus representing a relevant alternative to costly instrumental techniques for water quality assessment. In fact, in the last decade the application of chemical sensors and a multisensor system for rapid water quality evaluation is becoming more and more popular, since they may enable a low-cost and fast control of water safety, potability, and effectiveness of the purification process [23-27].

We previously demonstrated the application of a potentiometric E-tongue system for water toxicity estimation in terms of cyano-bacterial microcystin toxins (MCs) detection [28]. The importance of sensors selection and choice of an appropriate mathematical model relating to the response of the multisensor system and MCs content detected by the standard ultra-high-performance liquid 
chromatography method with diode array detection (UHPLC-DAD ) and by the colorimetric enzymatic approach were shown, and the prediction of MCs content in drinkable waters at concentrations lower than the provisional guideline value of World Health Organization (WHO) of $1 \mathrm{mg} / \mathrm{L}$ was demonstrated [29]. In the present study we report the results of potentiometric E-tongue application for classification of drinkable water spiked with different concentrations of geosmin (GE) and 2-methyl-isoborneol (MIB) in order to monitor the presence of these compounds at OTC level and to provide a timely detection of alarm situations in case of extreme pollution before drinking water is delivered to the end user.

\section{Materials and Methods}

\subsection{Reagents}

Isoborneol (IB) was purchased from Sigma-Aldrich (São Paulo, Brazil), ( \pm )-geosmin and 2-methylisoborneol (GE/MIB) (100 $\mathrm{\mu g} / \mathrm{mL}$ in methanol) were purchased from Sigma-Aldrich (Rome, Italy). Dimethyl sulfoxide (DMSO), methanol (MeOH), and tetrahydrofuran (THF) solvents were obtained from Carlo Erba Reagents (Rome, Italy). Membrane components, high molecular weight Poly(vinyl chloride) (PVC), bis(2-ethylhexyl) sebacate (DEHS) plasticizer, tridodecylmethyl ammonium chloride (TDMACl), potassium tetrakis-(4-chlorophenyl)borate (TpCIPBK) lipophilic additives, and nonactine ionophore were purchased from Sigma-Aldrich (Rome, Italy). THF was distilled prior to use and 5,10,15,20-tetraphenylporphyrin manganese(III) chloride ionophore ( $\mathrm{Mn}(\mathrm{TPP}) \mathrm{Cl}$ ) was synthesized and fully characterized according to the literature procedure [30]. Millipore grade water was used for aqueous solution preparation. All the other chemicals were of analytical grade and used without further purification.

\subsection{Sensor System}

Potentiometric multisensory system was composed of 8 sensors with two different types of sensing membranes: PVC-based solvent polymeric membranes doped with $\mathrm{Mn}(\mathrm{TPP}) \mathrm{Cl}$ (sensor A1) and nonactin (sensor $\mathrm{C} 1$ ) ionophores; and chalcogenide glass membranes doped with different metal salts (G2-Cu, G7-Tl, G8-Ag, G10-Cd, G11-Pb). The PVC-based solvent polymeric membranes were formed according to the previously reported method [31,32]. For this, all the membrane components (PVC 30-33 wt \%, plasticizer $60-66 \mathrm{wt} \%$, ion-exchanger $0.1-10 \mathrm{wt} \%$, and $1 \mathrm{wt} \%$ of ionophore) were dissolved in THF. The membrane cocktails were then cast in a $24 \mathrm{~mm}$ i.d. glass ring on a glass slide and the solvent was evaporated overnight. Discs of $9 \mathrm{~mm}$ in diameter were then cut out from the parent membrane and fixed with $10 \mathrm{wt} \%$ of PVC in cyclohexanone glue onto hollow PVC tubes that served as electrode bodies. The tubes were filled with a $0.01 \mathrm{~mol} / \mathrm{L}$ mixture of $\mathrm{NaCl}$ and salt solution containing the respective primary ions for every sensor: $\mathrm{Cl}^{-}$for $\mathrm{A} 1$, and $\mathrm{NH}_{4}{ }^{+}$for $\mathrm{C}$. $\mathrm{The} \mathrm{Ag} / \mathrm{AgCl}$ reference electrodes were immersed in the sensors' inner solution to close the electrical circuit. Chalcogenide glass sensors were purchased from Sensor Systems (St. Petersburg, Russia). For commercial chalcogenide glass sensors, Cu-wire/Ag-paste solid contact was employed instead of the inner filling solution and the inner reference electrode. The potentials of sensors were measured versus a saturated calomel reference electrode (SCE, AMEL, Milan, Italy), in a standard two-electrode configuration cell. Potentiometric measurements were performed with LiquiLab (ECOSENS srl, Rome, Italy) high-impedance analog-to-digital potentiometer. Prior to measurements, the sensors were soaked in $0.01 \mathrm{~mol} / \mathrm{L} \mathrm{NaCl}$ aqueous solution for at least $24 \mathrm{~h}$.

The response of the multisensory system to isoborneol was tested in $1.7 \times 10^{-10}-1.9 \times 10^{-6} \mathrm{~mol} / \mathrm{L}$ aqueous calibration solutions, prepared by the addition of calculated amounts of $1 \mu \mathrm{g} / \mathrm{mL}$ and $10 \mu \mathrm{g} / \mathrm{mL}$ stock solutions of IB in DMSO to Millipore grade water. Similarly, the response of the multisensory system to geosmin/2-methylisoborneol was tested in $1.5 \times 10^{-10}-1.2 \times 10^{-6} \mathrm{~mol} / \mathrm{L}$ aqueous calibration solutions, prepared by the addition of calculated amounts of $1 \mu \mathrm{g} / \mathrm{mL}$ and $10 \mu \mathrm{g} / \mathrm{mL}$ stock solutions of 
GE/MIB in $\mathrm{MeOH}$ to Millipore grade water. The schematic presentation of the experimental set-up and e-Tongue image is given in Figure 2.

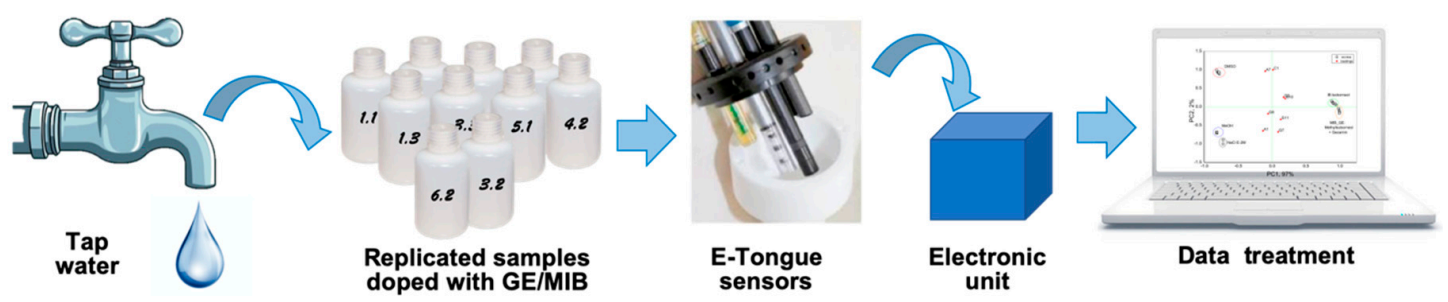

Figure 2. Schematic presentation of the employed measurement system.

\subsection{Water Samples}

Tap water samples with added geosmin/2-methylisoborneol pollutants in six different concentrations corresponding to 20, 100, 250, 500, 1000, and 10,000 ng/L were investigated. Each concentration was tested five times, and fresh tap water without pollutants was measured as a reference sample. Tap water was from regular water supply of "Tor Vergata" zone of Rome, Italy. The samples were prepared in $125 \mathrm{~mL}$ plastic bottles with a screw cap directly prior to the first measurement and were stored in the refrigerator prior to subsequent measurements. In total, 35 water samples were analyzed; three measurement sessions were performed during which the samples were measured in a random order.

\subsection{Data Processing}

Non-supervised principal component analysis (PCA) was used for data dispersion evaluation and samples identification [23].

Partial least squares discriminant analysis (PLS-DA) was applied for classification of tap water samples tainted with GE/MIB at two concentration levels: the same OTC order from 20 to $100 \mathrm{ng} / \mathrm{L}$ and at higher concentrations from 0.25 to $10 \mathrm{mg} / \mathrm{L}$. The PLS regression method was applied to correlate the E-tongue response to known GE/MIB content in tested samples. The constructed PLS-DA and PLS models were validated using the one-leave-out cross-validation for first approximation; where the data set was representative enough and the random split test set was employed.

The root mean square error of calibration (RMSEC), root mean square error of validation (RMSEV), and the correlation coefficient of predicted versus measured correlation line, $R^{2}$, were used to evaluate the efficiency of the obtained PLS models. The chemometric treatment was performed with Unscrambler software (v. 9.7, 2007, CAMO Software AS, Oslo, Norway).

\section{Results and Discussion}

On the first step of the study the responses of E-tongue sensors were registered in the model solutions of IB and GE/MIB prepared on distilled water background in the concentration range from $25 \mathrm{ng} / \mathrm{L}$ to $300 \mu \mathrm{g} / \mathrm{L}$ in order to simulate the tap water with unpleasant organoleptic characteristics, and to evaluate the ability of the multisensor system to detect these pollutants at OTC cut-off level. For this purpose, we employed the E-tongue system reported in our previous research dedicated to the microcystin toxins screening in potable water [28]. Due to the frequent co-occurrence of microcystins and GE and MIB taste-and-odor compounds in drinking water [33], the E-tongue system may provide a simultaneous and important evaluation of water toxicity and organoleptic potability, thus signaling possible alarm situations corresponding to a high level of drinking water pollution prior to its delivery to end users.

The responses of several selected sensors from E-tongue array, namely polymeric membrane sensor $\mathrm{C} 1$, chalcogenide glass sensors $\mathrm{G} 7-\mathrm{Tl}, \mathrm{G} 8-\mathrm{Ag}$, and polycrystalline sensor A7 toward growing concentrations of GE/MIB are shown in Figure 3. The distinct and correlated variation of sensor potentials both for polymeric cation-sensitive sensor $\mathrm{C} 1$ and polycrystalline anionic membrane A7 should be noticed; such a variation is possibly a result of GE/MIB partitioning from analyzed aqueous 
media and further accumulation on the sensor membrane surface. In the case of chalcogenide glass electrodes, the significant potential drop occurs as a result of electrostatic interactions among GE/MIB (probably partially protonated) and positively (G8-Ag) or negatively (G7-Tl) charged membranes. Hence, through the combination of selected sensors responses and application of a suitable chemometric modeling method the possibility to track the taste-and-odor-causing compounds presence and content can be considered.

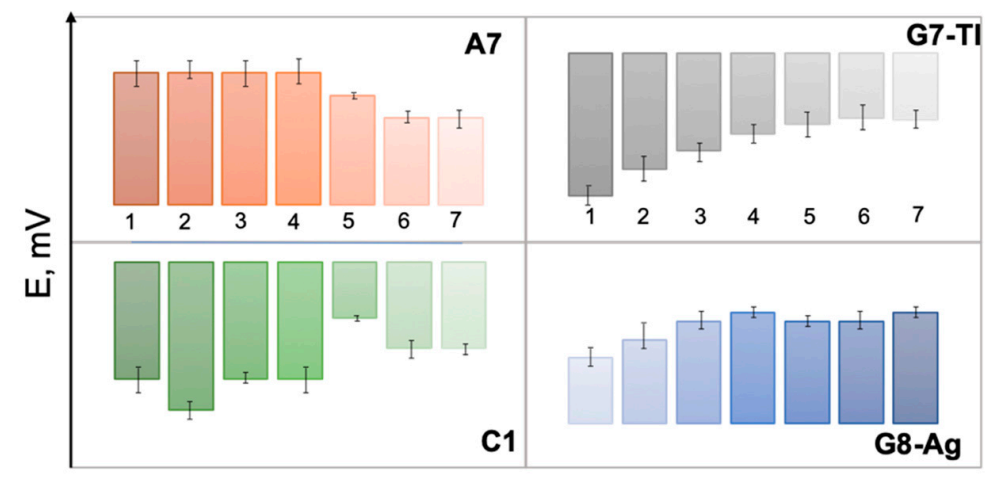

Figure 3. The responses of individual sensors A7, C1, G7-Tl, and G8-Ag in aqueous solutions of geosmin (GE) and 2-methyl-isoborneol (MIB) in concentrations (from left to right) (1): 25, (2): 50, (3): 100, (4): $500 \mathrm{ng} / \mathrm{L},(5): 1,(6): 10$, and (7): $100 \mu \mathrm{g} / \mathrm{L}$.

With an aim to distinguish the presence of taste-and-odor-causing compounds in aqueous solutions we first evaluate the dispersion of sensor array data obtained in all tested samples with the PCA method. As seen in Figure 4, the exploratory PCA technique indicates the ability of the E-tongue system to clearly distinguish among aqueous solutions of MIB and GE (prepared from standard solution of $100 \mu \mathrm{g} / \mathrm{mL}$ in methanol) and solutions of pure methanol (MeOH) in water. At the same time, a greater influence of DMSO solvent (used to prepare IB stock solution) on E-tongue sensors' response is obtained, and this causes some difficulties in a proper discrimination between solutions of IB in DMSO/water and aqueous solutions of DMSO. The highest loadings, and hence the highest influence on solutions discrimination, is found for anion-sensitive sensors A1, A7, nonactin-based cationic sensor C1, and Tl-doped chalcogenide-glass electrode G7 with distinct redox sensitivity.

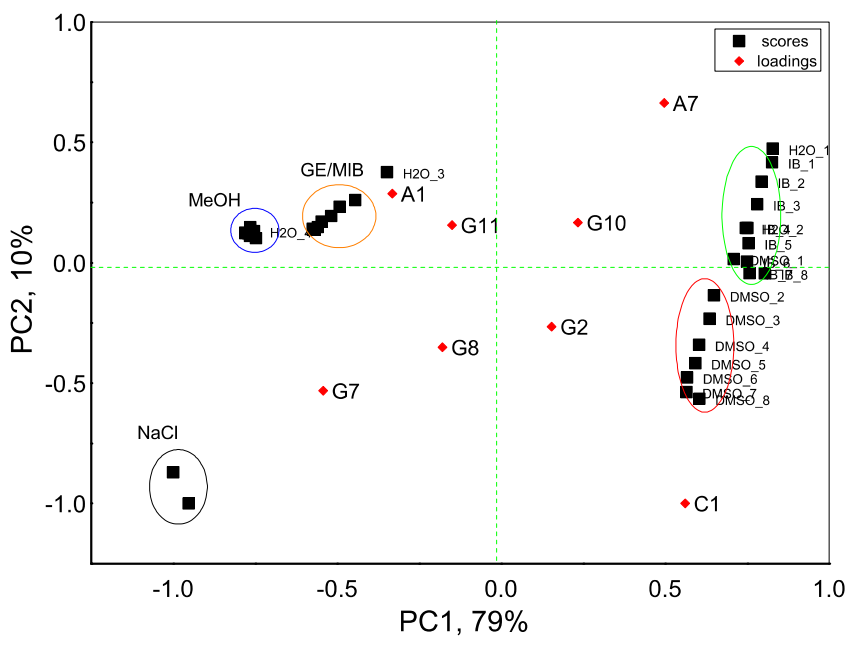

Figure 4. Principal component analysis (PCA) bi-plot result of E-tongue application for recognition of $\mathrm{IB}, \mathrm{DMSO}, \mathrm{GE} / \mathrm{MIB}$, and $\mathrm{MeOH}$ aqueous solutions in concentration range from $25 \mathrm{ng} / \mathrm{L}$ to $300 \mu \mathrm{g} / \mathrm{L}$. The numbers in the sample labels correspond to the progressive measurement number. 
Due to the sensors drift observed between different days of measurements, mathematical drift correction is required $[29,34]$; we normalize the sensors' response considering the sensors readings in distilled water prior to the calibration as reference values. First, the differences between sensors readings in water during the first measurement day and the sensors' readings in water background solution during the following measurements, $\mathrm{D}_{\mathrm{H} 2 \mathrm{O}}$, were calculated. Then the E-tongue sensors responses in IB and GE/MIB solutions are normalized as:

$$
\begin{aligned}
& S_{\text {sn_IB }}=R_{I B \_n}-R_{D M S O \_n}+D_{H 2 O} \\
& \mathrm{~S}_{\mathrm{Sn} \_\mathrm{MIB} \_\mathrm{GE}}=\mathrm{R}_{\mathrm{MIB} \_\mathrm{GE} \_\mathrm{n}}-\mathrm{R}_{\mathrm{MeOH} \_\mathrm{n}}+\mathrm{D}_{\mathrm{H} 2 \mathrm{O}}
\end{aligned}
$$

where $\mathrm{S}_{\mathrm{Sn} \_ \text {IB }}$ and $\mathrm{S}_{\mathrm{Sn} \_ \text {MIB_GE }}$ are valued as normalized responses of sensor $\mathrm{s}$ in calibration solution $\mathrm{n}$

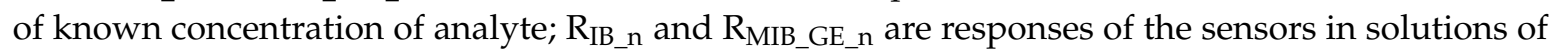
IB and MIB_GE respectively; $R_{\text {DMSO_n }}$ and $\mathrm{R}_{\mathrm{MeOH}_{-} n}$ are responses in aqueous solutions of solvents, $\mathrm{DMSO}$ and $\mathrm{MeOH}$ correspondingly; $\mathrm{D}_{\mathrm{H} 2 \mathrm{O}}$ is sensors drift correction value.

As seen from Figure 5, a clear separation of IB and GE/MIB solutions from pure $\mathrm{MeOH}$ and DMSO solvents is obtained for normalized data, especially along the PC1 axis; while the concentration gradient of odor-causing compounds is clearly noted along PC2.

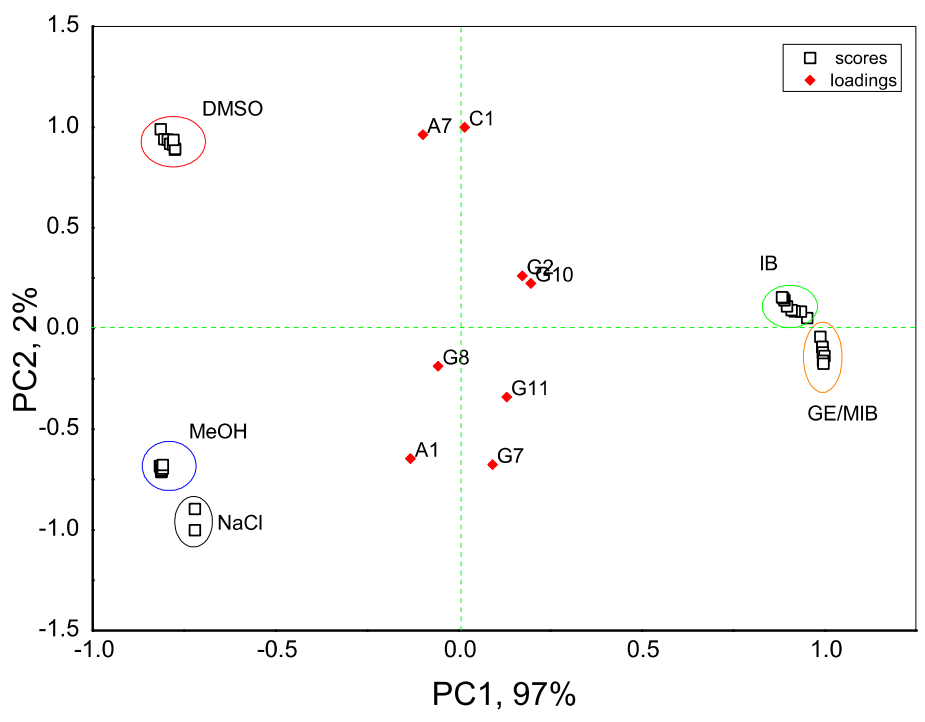

Figure 5. PCA bi-plot of E-tongue response in IB, DMSO, GE/MIB, and $\mathrm{MeOH}$ aqueous solutions after data normalization and solvent influence minimization.

Moreover, the application of the partial squares linear regression method, PLS1, demonstrated the correlation between E-tongue sensor responses and IB and GE/MIB content in calibration solutions in a semilogarithmic scale (Figure 6). One-leave-out cross validation method is used due to the small size of the initial data set. The adequate predictive power of E-tongue was found for IB in DMSO solutions with $R_{\text {cal }}^{2}=0.998$ and $R_{\text {val }}^{2}=0.906(99.3 \%$ and $87.1 \%$ of total explained variance at calibration and validation steps, respectively; 5PCs). GE/MIB methanol/aqueous solutions have a lower validation correlation coefficient, $R_{\text {val }}^{2}=0.695\left(R_{\text {cal }}^{2}=0.998\right.$, total explained variance: $96.4 \%$ and $69.7 \%$ for calibration and validation respectively; $4 \mathrm{PCs})$. 

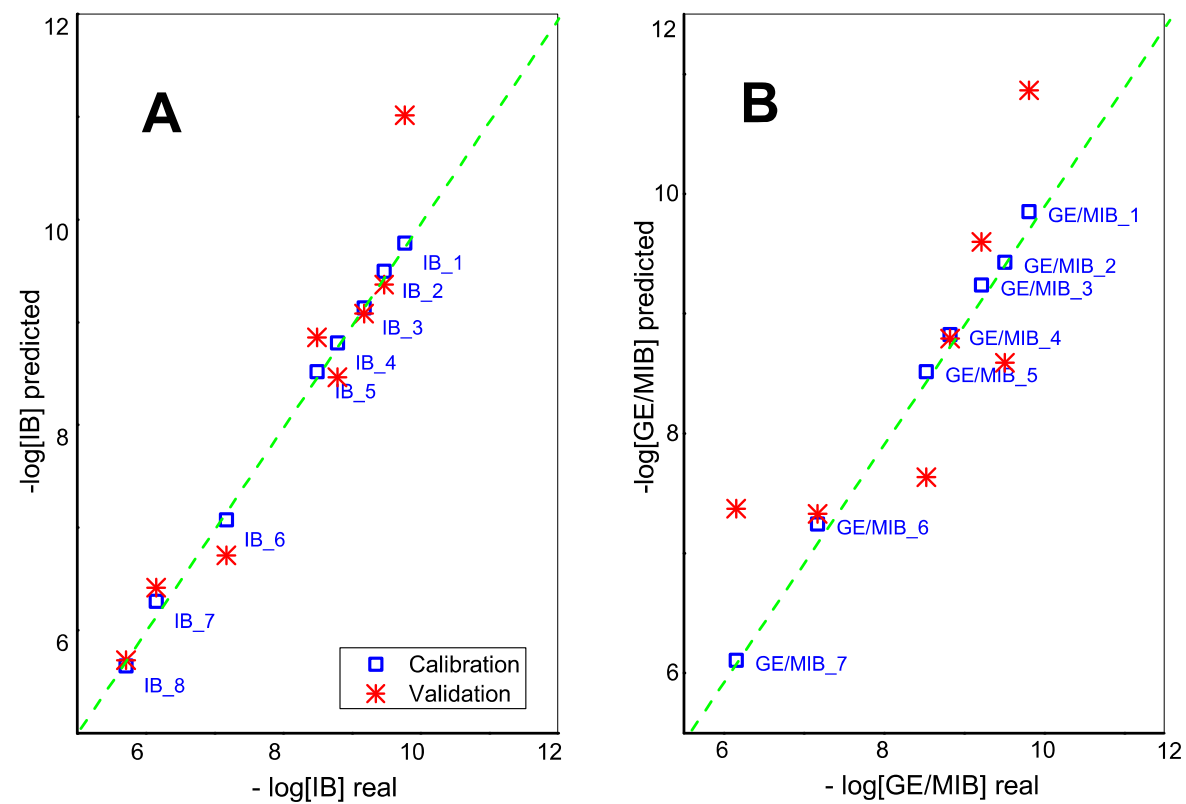

Figure 6. The PLS1 correlation result for (A) IB and (B) GE/MIB content determined by means of potentiometric E-tongue system.

At the next step of our study, tests in tap water samples spiked with different concentrations of GE/MIB are performed in order for the PLS-DA model to discriminate tap water samples containing these compounds at two concentration levels: the same OTC order from 20 to $100 \mathrm{ng} / \mathrm{L}$ (class 1 ) and at higher concentrations from 0.25 to $10 \mathrm{mg} / \mathrm{L}$ (class 2). The PLS-DA was conducted on a set composed of 30 samples: 15 samples of class 1 and 15 samples of class 2, respectively. The confusion matrix of one-leave-out PLS-DA cross validation is reported in Table 1, while the three-dimensional (3D) score-plot of discrimination results is shown in Figure 7. In the table, rows indicate the expected GE/MIB spiked tap water class and columns correspond to those predicted.

Table 1. Partial least square discriminant analysis (PLS-DA) confusion matrix of tap water samples classification to spiked GE/MIB concentration content.

\begin{tabular}{ccc}
\hline \multirow{2}{*}{ Expected } & \multicolumn{2}{c}{ Predicted } \\
\cline { 2 - 3 } & $\begin{array}{c}\text { Class 1, Low Content } \\
\mathbf{( 2 0 - 1 0 0 ~} \mathbf{~ g / ~ L ) ~}\end{array}$ & $\begin{array}{c}\text { Class 2, High Content } \\
\mathbf{( 0 . 2 5 - 1 0 ~} \mathbf{~ g / L )}\end{array}$ \\
\hline Class 1 & 13 & 1 \\
Class 2 & 1 & 12 \\
Non classified & 2 & 1 \\
\hline
\end{tabular}

Only one sample with high taste-and-odor-causing compounds concentration is misclassified, while another three samples could not be attributed to any class. The correct classification of $83 \%$ of samples is obtained and this preliminary result is satisfactory, considering the very low OTC level of the pollutants investigated. 


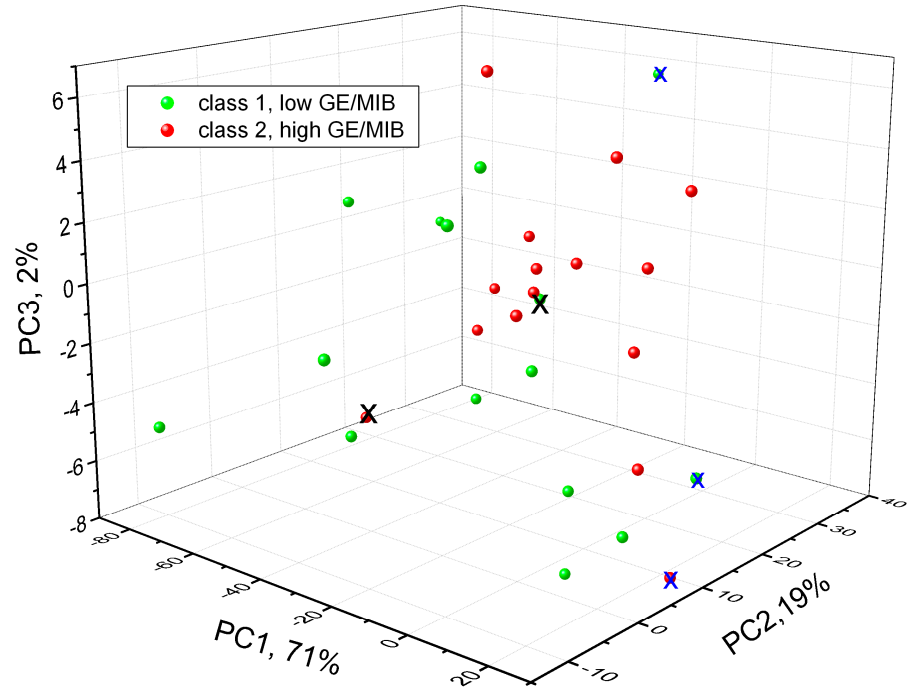

Figure 7. Three-dimensional (3D)-scores plot of PLS-DA GE/MIB detection in tap water by means of potentiometric E-tongue. X: misclassified samples; x: sample with no class attribution.

\section{Conclusions}

A possibility to assess the taste-and-odor-causing pollutants, geosmin (GE) and 2-methyl-isoborneol (MIB) in drinkable water by means of potentiometric E-tongue was investigated. The preliminary tests have demonstrated the E-tongue utility to discriminate tap water contaminated with GE/MIB at low (20 to $100 \mathrm{ng} / \mathrm{L}$ ) and high ( 0.25 to $10 \mathrm{mg} / \mathrm{L}$ ) concentration levels. Obtained results permit to consider the developed E-tongue system as a promising easy-to-handle tool for assessment of GE/MIB species, and to provide a timely detection of alarm situations in case of extreme pollution by these compounds before drinking water is delivered to the end user in time to allow decision making which is of key importance in water treatment stations. Such a system, being installed in the potable water withdrawal and distribution systems, and connected to the control center through wireless networks, could be implemented for economical and real-time water quality monitoring.

Author Contributions: Conceptualization, L.H.C.M.; investigation, methodology, and original draft preparation, L.L.; validation, D.S.C., L.H.C.M. and I.J.; resources, R.P.; data curation, L.L.; review and editing, L.L., D.S.C. and E.O.; supervision, R.P., C.D.N. and A.L.; project administration, L.H.C.M. and A.L.; funding acquisition, E.O., A.L., L.H.C.M., D.S.C. and R.P. All authors have read and agreed to the published version of the manuscript.

Funding: This research was partially funded by Fundação de Amparo à Pesquisa do Estado de São Paulo (PITE-FAPESP process \# 2013/50440-7) and Conselho Nacional de Desenvolvimento Científico e Tecnológico-CNPq (process \# 303796/2014-6) (Brazil). D.S.C. also thanks FAPESP through process \# 2017/12174-4. A.L. gratefully acknowledges the support of RFBR project 18-53-80010 BRICS-t; E.O. would like to thank the support of the Government of Russian Federation, Grant 08-08.

Conflicts of Interest: The authors declare no conflicts of interest.

\section{References}

1. UNESCO. Managing Water Under Uncertainty and Risk; The United Nations: New York, NY, USA, 2012. Available online: https://www.unwater.org/publications/managing-water-uncertainty-risk/ (accessed on 3 February 2020).

2. World Health Organization. Guidelines for Drinking-Water Quality: Fourth Edition Incorporating the First Addendum; WHO: Geneva, Switzerland, 2017; 631p. Available online: https:/www.who.int/water_sanitation_ health/publications/gdwq4-1st-addendum/en/ (accessed on 3 February 2020).

3. The European Parliament and The Council of The European Union. Directive 2000/60/EC of the European Parliament and of the Council Establishing a Framework for the Community Action in the Field of Water Policy (EU Water Framework Directive). 2000. Available online: https://www.eea.europa.eu/policy-documents/ directive-2000-60-ec-of (accessed on 3 February 2020). 
4. Technologies and Techniques for Early Warning Systems to Monitor and Evaluate Drinking Water Quality: State of-the-Art Review; United States Environmental Protection Agency, Office of Water: Washington, DC, USA, 2005. Available online: https://nepis.epa.gov (accessed on 3 February 2020).

5. UNEP. Global Drinking Water Quality Index Development and Sensitivity Analysis Report. 2007. Available online: https://www.un.org/waterforlifedecade/pdf/global_drinking_water_quality_index.pdf (accessed on 3 February 2020).

6. Graham, J.L.; Loftin, K.A.; Meyer, M.T.; Ziegler, A.C. Cyanotoxin Mixtures and Taste-and-Odor Compounds in Cyanobacterial Blooms from the Midwestern United States. Environ. Sci. Technol. 2010, 44, 7361-7368. [CrossRef] [PubMed]

7. Srinivasan, R.; Sorial, G.A. Treatment of taste and odor causing compounds 2-methyl isoborneol and geosmin in drinking water: A critical review. J. Environ. Sci. 2011, 23, 1-13. [CrossRef]

8. Watson, S.B.; Ridal, J.; Boyer, G.L. Taste and odor and cyanobacterial toxins: Impairment, prediction, and management in the Great Lakes. Can. J. Fish. Aquat. Sci. 2008, 65, 1779-1796. [CrossRef]

9. Lloyd, S.W.; Lea, J.M.; Zimba, P.V.; Grimm, C.C. Rapid analysis of geosmin and 2-methylisoborneol in water using solid phase micro extraction procedures. Water Res. 1998, 32, 2140-2146. [CrossRef]

10. UNEP. Single-Use Plastics: A Roadmap for Sustainability. 2018. Available online: https://wedocs.unep. org/bitstream/handle/20.500.11822/25496/singleUsePlastic_sustainability.pdf?sequence=1\&isAllowed=y (accessed on 3 February 2020).

11. UN Environment. Available online: https://www.unenvironment.org/interactive/beat-plastic-pollution (accessed on 30 December 2019).

12. Bristow, R.L.; Young, I.S.; Pemberton, A.; Williams, J.; Maher, S. An extensive review of the extraction techniques and detection methods for the taste and odour compound geosmin (trans-1, 10-dimethyl-trans-9-decalol) in water. TrAC Trends Anal. Chem. 2019, 110, 233-248. [CrossRef]

13. Kaziur, W.; Salemi, A.; Jochmann, M.A.; Schmid, T.C. Automated determination of picogram-per-liter level of water taste and odor compounds using solid-phase microextraction arrow coupled with gas chromatography-mass spectrometry. Anal. Bioanal. Chem. 2019, 411, 2653-2662. [CrossRef] [PubMed]

14. Lian, H.; Lin, Q.; Sun, G. Automated ultratrace determination of musty odiferous compounds from environmental waters by online purge and trap (P\&T) gas chromatography-mass spectrometry (GC-MS). Instrum. Sci. Technol. 2019, 47, 278-291.

15. Hensarling, T.P.; Waage, S.K. A bromine-based color reaction for the detection of geosmin. J. Agric. Food Chem. 1990, 38, 1236-1237. [CrossRef]

16. Chung, S.Y.; Vercellotti, J.R.; Johnsen, P.B.; Klesius, P.H. Development of an enzyme-linked immunosorbent assay for geosmin. J. Agric. Food Chem. 1991, 39, 764-769. [CrossRef]

17. Chung, S.-Y.; Johnsen, P.B.; Klesius, P.H. Development of an ELISA Using Polyclonal Antibodies Specific for 2-Methylisoborneol. J. Agric. Food Chem. 1990, 38, 410-415. [CrossRef]

18. Plhak, L.C.; Park, E.S. High-Affinity Monoclonal Antibodies for Detection of the Microbial Metabolite, 2-Methylisoborneol. J. Agric. Food Chem. 2003, 51, 3731-3736. [CrossRef] [PubMed]

19. Ji, H.S.; McNiven, S.; Lee, K.H.; Saito, T.; Ikebukuro, K.; Karube, I. Increasing the sensitivity of piezoelectric odour sensors based on molecularly imprinted polymers. Biosens. Bioelectron. 2000, 15, 403-409. [CrossRef]

20. Stuetz, R.M.; White, M.; Fenner, R.A. Use of an electronic nose to detect tainting compounds in raw and treated potable water. Aqua J. Water Serv. Res. Technol. 1998, 47, 223-228.

21. Son, M.; Cho, D.G.; Lim, J.H.; Park, J.; Hong, S.; Ko, H.J.; Park, T.H. Real-time monitoring of geosmin and 2-methylisoborneol, representative odor compounds in water pollution using bioelectronic nose with human-like performance. Biosens. Bioelectron. 2015, 74, 199-206. [CrossRef] [PubMed]

22. Braga, G.S.; Paterno, L.G.; Fonseca, F.J. Performance of an electronic tongue during monitoring 2-methylisoborneol and geosmin in water samples. Sens. Actuators B Chem. 2012, 171-172, 181-189. [CrossRef]

23. Lvova, L.; Kirsanov, D.; Legin, A.; Di Natale, C. Multisensor Systems for Chemical Analysis: Materials and Sensors; Pan Stanford Publishing: Singapore, 2013; p. 392, ISBN 978-981441116-5; 978-981441115-8.

24. Lvova, L.; Di Natale, C.; Paolesse, R. Chemical Sensors for Water Potability Assessment. In Bottled and Packaged Water, The Science of Beverages; Grumezescu, A.M., Holban, A.M., Eds.; Woodhead Publishing: Cambridge, UK, 2019; Volume 4, pp. 177-208. [CrossRef] 
25. Kuchmenko, T.A.; Lvova, L.B. A Perspective on Recent Advances in Piezoelectric Chemical Sensors for Environmental Monitoring and Foodstuffs Analysis. Chemosensors 2019, 7, 39. [CrossRef]

26. Legin, E.; Zadorozhnaya, O.; Khaydukova, M.; Kirsanov, D.; Rybakin, V.; Zagrebin, A.; Ignatyeva, N.; Ashina, J.; Sarkar, S.; Mukherjee, S.; et al. Rapid Evaluation of Integral Quality and Safety of Surface and Waste Waters by a Multisensor System (Electronic Tongue). Sensors 2019, 19, 2019. [CrossRef]

27. Facure, M.H.M.; Mercante, L.A.; Mattoso, L.H.C.; Correa, D.S. Detection of trace levels of organophosphate pesticides using an electronic tongue based on graphene hybrid nanocomposites. Talanta 2017, 167, 59-66. [CrossRef]

28. Lvova, L.; Guanais Gonçalves, C.; Petropoulos, K.; Micheli, L.; Volpe, G.; Kirsanov, D.; Legin, A.; Viaggiu, E.; Congestri, R.; Guzzella, L.; et al. Electronic tongue for microcystins screening in waters. Biosens. Bioelectron. 2016, 80, 154-160. [CrossRef]

29. Panchuk, V.; Lvova, L.; Kirsanov, D.; Guanais Goncalves, C.; Di Natale, C.; Paolesse, R. Extending electronic tongue calibration lifetime through mathematical drift correction: Case study of microcystin toxicity analysis in waters. Sens. Actuators B Chem. 2016, 237, 962-968. [CrossRef]

30. Smith, K.M. (Ed.) Porphyrins and Metallo-Porphyrins; Elsevier: Amsterdam, The Netherlands, 1975.

31. Levitchev, S.S.; Smimova, A.L.; Khitrova, V.L.; Lvova, L.B.; Bratov, A.V.; Viasov, Y.G. Photocurable carbonate-selective membranes for chemical sensors containing lipophilic additives. Sens. Actuators B Chem. 1997, 44, 397-401. [CrossRef]

32. Lvova, L.; Pudi, R.; Galloni, P.; Lippolis, V.; Di Natale, C.; Lundstrom, I.; Paolesse, R. Multi-transduction sensing films for Electronic Tongue applications. Sens. Actuators B Chem. 2015, 207B, 1076-1086. [CrossRef]

33. Shang, L.; Feng, M.; Xu, X.; Liu, F.; Ke, F.; Li, W. Co-occurrence of microcystins and taste-and-odor compounds in drinking water source and their removal in a full-scale drinking water treatment plant. Toxins 2018, 10, 26. [CrossRef] [PubMed]

34. Panchuk, V.; Semenov, V.; Lvova, L.; Legin, A.; Kirsanov, D. Response Standardization for Drift Correction and Multivariate Calibration Transfer in Electronic Tongue studies. In Biomimetic Sensing: Methods and Protocols, Methods in Molecular Biology; Fitzgerald, J.E., Fenniri, H., Eds.; Humana: New York, NY, USA, 2019; Volume 2027, pp. 181-194. [CrossRef]

(C) 2020 by the authors. Licensee MDPI, Basel, Switzerland. This article is an open access article distributed under the terms and conditions of the Creative Commons Attribution (CC BY) license (http://creativecommons.org/licenses/by/4.0/). 